\title{
Not just a fracture
}

\author{
Margot Van de Vijver
}

Department of General Paediatrics, King's College Hospital, London, UK

\section{Correspondence to}

Dr Margot van de Vijver, mvandevijver@doctors.org.uk

\section{DESCRIPTION}

An 8-month-old girl presented with a reluctance to weight bear on her left leg following a trivial, low impact fall. X-rays showed a fracture of the distal third of the left tibial shaft.

The child's general health and development were normal. There was no suspicion of non-accidental

\section{RED DOT}

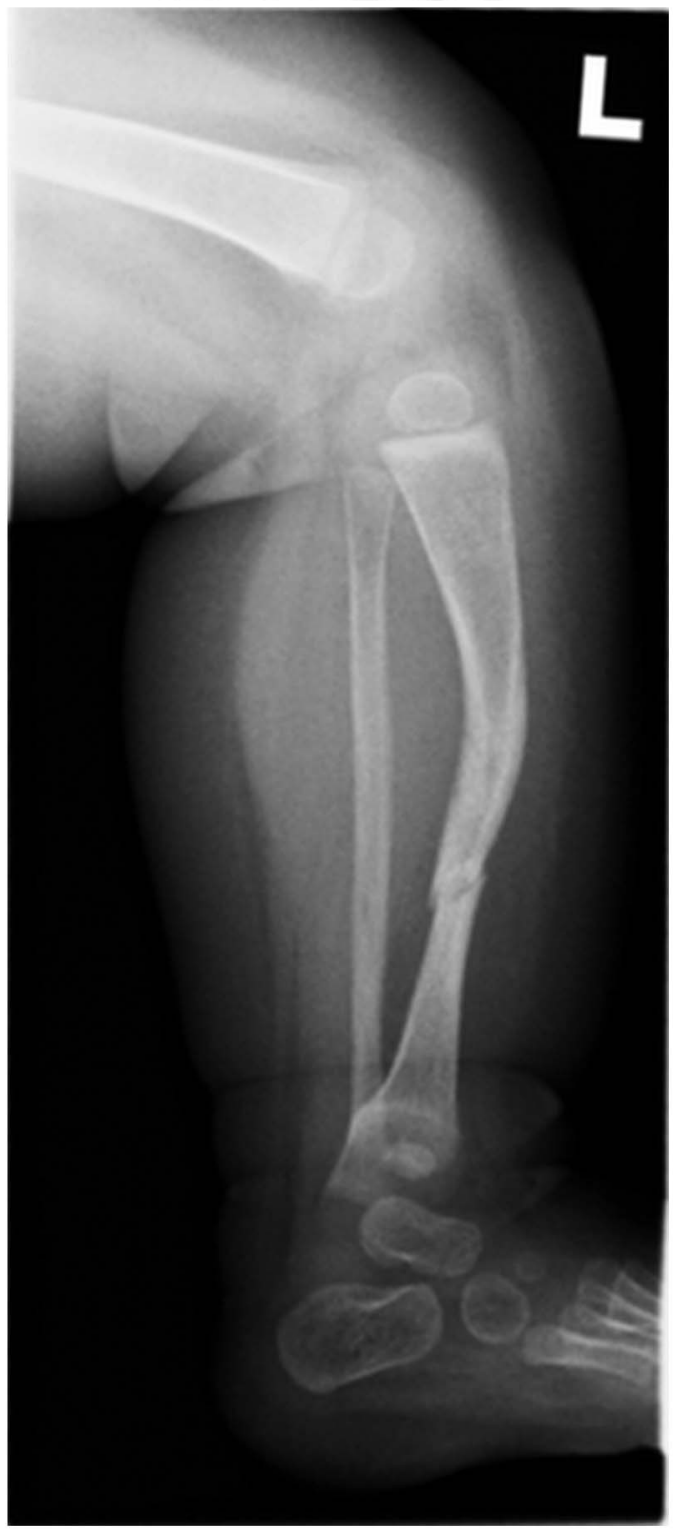

Figure 1 Lateral radiograph of the patient's left leg on initial presentation revealing anterolateral bowing of the tibia, thinning of the long bone cortex and a secondary pathological fracture. injury from history or enquiry. Investigations excluded nutritional deficiencies and endocrinemetabolic disorders. A skeletal survey showed no other abnormalities. The radiologist raised the possibility of underlying neurofibromatosis type 1 (NF1) in view of the anterolateral bowing of the tibia (see figures 1 and 2). However, as there was no family history and an otherwise normal examination, the National Institutes of Health Consensus Development Conference diagnostic criteria for NF1 were not met. ${ }^{1}$

On follow up, 4 months after injury, examination revealed two iris hamartomas (Lisch nodules) and three café-au-lait macules. The clinical geneticist confirmed NF1 based on the new findings and

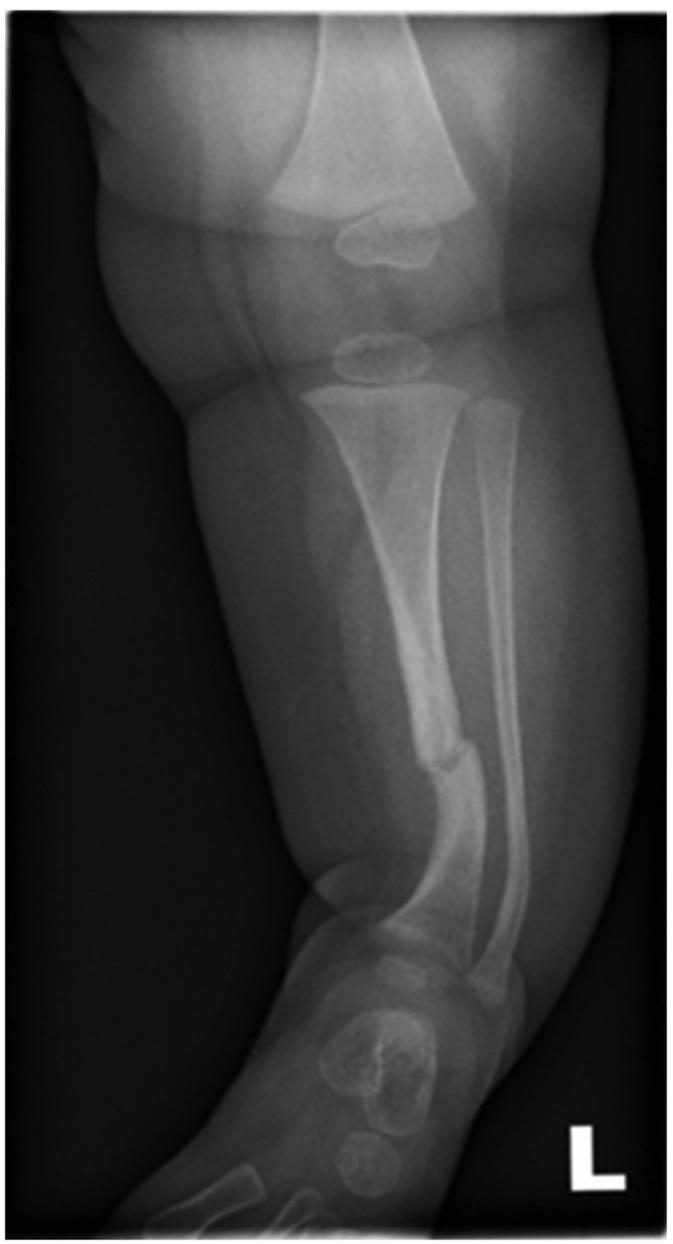

Figure 2 Anterior-posterior radiograph of the patient's left leg on initial presentation revealing anterolateral bowing of the tibia, thinning of the long bone cortex and a secondary pathological fracture. 


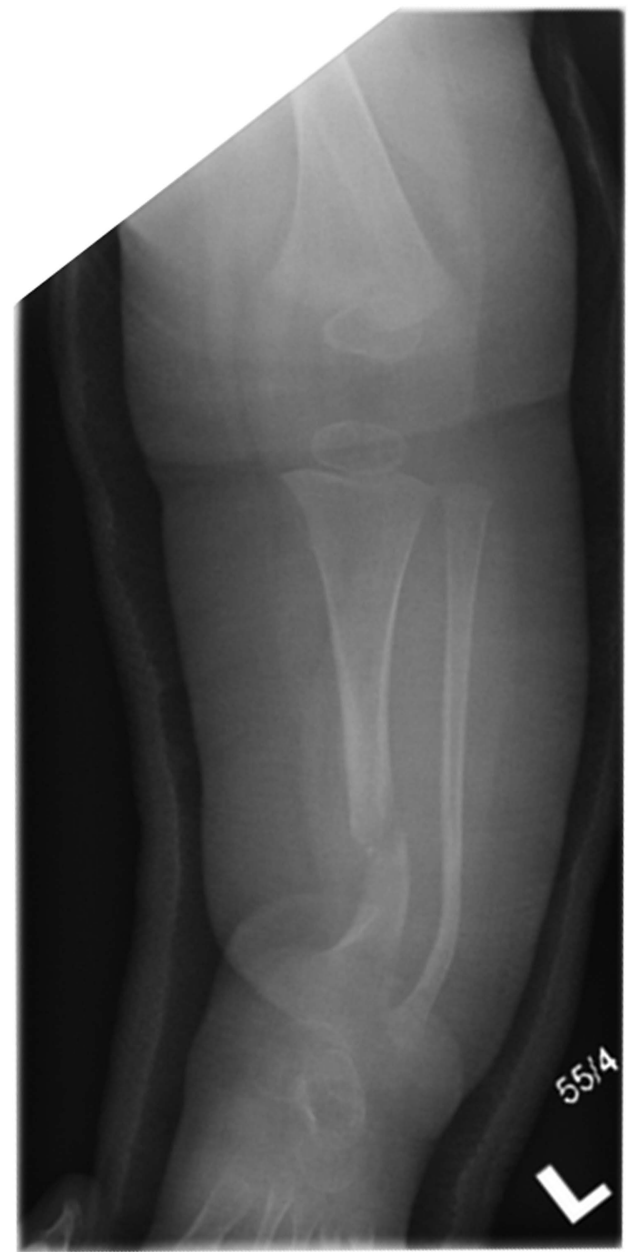

Figure 3 An anterior-posterior radiograph taken 8 weeks after injury showing the patient's leg in an above-knee plaster with persistent bowing of the tibia and widening of the tibial fracture gap with ill-defined fracture margins suggestive of non-union. This is consistent with developing pseudarthrosis of the tibia. a distinctive osseous tibial lesion with developing pseudarthrosis (see figure 3), thus meeting two of the seven diagnostic criteria.

NF1 is common but the associated skeletal abnormalities are rare and include long bone dysplasia and kyphoscoliosis. ${ }^{2}$ Long bone dysplasia is seen in $2 \%$ of NF1 patients ${ }^{3}$ and typically involves the lower third of the tibia, is most often unilateral and always presents with anterolateral bowing. The first clue to NF1 diagnosis, in those with dysplasia, is commonly a trivial injury leading to fracture in the first 18 months of life.

\section{Learning points}

- Neurofibromatosis type 1 (NF1) should be considered as a differential diagnosis for a fracture occurring spontaneously or after trivial injury.

- Long bone dysplasia is a cardinal feature of NF1 and typically involves the distal third of the tibia and presents with anterolateral bowing.

- Early recognition of NF 1 with bone dysplasia is crucial and referral to a specialist orthopaedic surgeon is essential in view of delayed healing and the risk of resulting pseudarthrosis.

Competing interests None.

Patient consent Obtained.

Provenance and peer review Not commissioned; externally peer reviewed.

\section{REFERENCES}

1 Neurofibromatosis. Natl Inst Health Consens Dev Conf Consens Statement. 1987:6:1-19.

2 Crawford AH, Schorry EK. Neurofibromatosis in children: the role of the orthopaedist. J Am Acad Orthop Surg 1999;7:217-30.

3 Ferner RE, Huson SM, Thomas N, et al. Guidelines for the diagnosis and management of individuals with neurofibromatosis 1. J Med Genet 2007;44:81-8.

Copyright 2014 BMJ Publishing Group. All rights reserved. For permission to reuse any of this content visit

http://group.bmj.com/group/rights-licensing/permissions.

BMJ Case Report Fellows may re-use this article for personal use and teaching without any further permission.

Become a Fellow of BMJ Case Reports today and you can:

- Submit as many cases as you like

- Enjoy fast sympathetic peer review and rapid publication of accepted articles

- Access all the published articles

- Re-use any of the published material for personal use and teaching without further permission

For information on Institutional Fellowships contact consortiasales@bmjgroup.com

Visit casereports.bmj.com for more articles like this and to become a Fellow 